\title{
Cold-water coral reef frameworks, megafaunal communities and evidence for coral carbonate mounds on the Hatton Bank, north east Atlantic
}

\author{
J. M. Roberts · L.-A. Henry · D. Long · J. P. Hartley
}

Published online: 20 May 2008

(C) Springer-Verlag 2008

\section{Erratum to: Facies}

DOI 10.1007/s10347-008-0140-x

At the end of Table 2 two of the fish species names are misspelled:

Helicolinus dactylopterus should be Helicolenus dactylopterus and Galeus malastomas should be Galeus melastomus.

The online version of the original article can be found under doi:10.1007/s10347-008-0140-x.

J. M. Roberts $(\square) \cdot$ L.-A. Henry

Scottish Association for Marine Science,

Dunstaffnage Marine Laboratory, Oban,

Argyll PA37 1QA, UK

e-mail: murray.roberts@sams.ac.uk; robertsjm@uncw.edu

\section{J. M. Roberts}

Center for Marine Science,

University of North Carolina at Wilmington,

5600 Marvin K. Moss Lane, Wilmington, NC 28409, USA

D. Long

British Geological Survey, Murchison House,

West Mains Road, Edinburgh EH9 3LA, UK

J. P. Hartley

Hartley Anderson Ltd., Blackstone, Dudwick,

Ellon, Aberdeenshire AB41 8ER, UK 